\title{
Autosomal dominant Charcot-Marie- Tooth disease type 2 with giant axons
}

INSERM

\section{Source}

INSERM. (1999). Orphanet: an online rare disease and orphan drug data base. Autosomal dominant Charcot-Marie-Tooth disease type 2 with giant axons. ORPHA:401964

Autosomal dominant Charcot-Marie-Tooth disease type 2 with giant axons is a rare subtype of axonal hereditary motor and sensory neuropathy characterized by distal muscle weakness and atrophy (principally of peroneal muscles) associated with distal sensory loss (tactile, vibration), pes cavus present since infancy or childhood, and axonal swelling with neurofilament accumulation on nerve biopsy. Other features may include hand muscle involvement, hypo/arreflexia, gait disturbances, muscle cramps, toe abnormalities and mild cardiomyopathy. 